\title{
Liquid Chromatography-Mass Spectrometry of Arsenic Compounds Using the Electrospray Ionization with Postcolumn Addition of Methanol
}

\author{
Naoto Shimizu, Yoshinori Inoue, Shigeki Daishima and Kenji Yamaguchi \\ Yokogawa Analytical Systems Inc., 2-11-13 Nakacho, Musashino, Tokyo 180-0006, Japan
}

Keywords HPLC/MS, arsenic compounds, electrospray ionization

It has been well known that inorganic arsenic compounds can be carcinogenic to humans. ${ }^{1}$ Most mammals convert inorganic arsenic compounds to low toxicity monomethylarsonic acid (MMAA), dimethylarsinic acid (DMAA) or trimethylarsine oxide (TMAO) by methylation. ${ }^{2,3}$ As the toxicological properties of arsenic compounds depend on their chemical forms, it has been demonstrated that the analysis of every chemical form is very important. Although the LC-ICP/MS is sensitive and precise, the LC-ICP/MS does not give any information on speciation. ${ }^{4-6}$ On the other hand, the LC/MS is a good tool for qualification and quantifi-

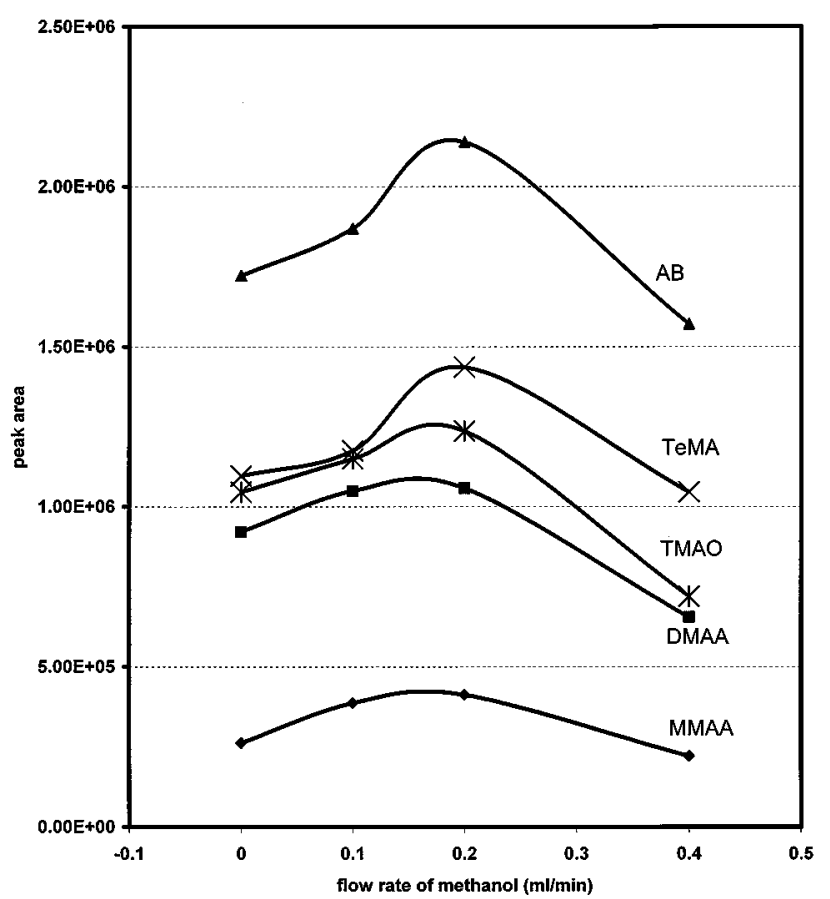

Fig. 1 The relationships between the flow rates of methanol and the peak areas of arsenic compounds. Conditions: carrier, $8 \mathrm{mM} \mathrm{HNO}_{3} / 5 \mathrm{mM} \mathrm{NH}_{4} \mathrm{NO}_{3}, 0.4 \mathrm{ml} / \mathrm{min}$; drying gas, $\mathrm{N}_{2}$ (13 $\left.1 / \mathrm{min}, 350{ }^{\circ} \mathrm{C}\right)$; nebulizer, $\mathrm{N}_{2}$ (60 psi); accelerating voltage, 80 $\mathrm{V}$; polarity, positive scan mode; sample, $10 \mathrm{ng} / \mu \mathrm{l}$ each, $10 \mu \mathrm{l}$ inject; postcolumn, methanol. cation. We have previously reported the appropriate mobile phase and the MS conditions for the arsenic compounds using LC/MS. ${ }^{7}$ Since it is known that the addition of an organic solvent is useful to increase the sensitivity on electrospray ionization (ESI), we examined the postcolumn addition of methanol for improvement of the linearity, detection limit and repeatability of the method.

\section{Experimental}

Organoarsenic species MMAA, DMAA, TMAO, tetramethylarsonium (TeMA) iodide, and arsenobetaine (AB), were purchased from Tri Chemical Laboratories Inc. (Yamanashi, Japan). Other reagents (each analytical grade) were purchased from Wako Pure Chemical Industries. Deionized water was obtained from a MilliQ system (Nihon Millipore, Tokyo, Japan). The LC/MS equipment was Model HP1100 series HPLC with MS (Hewlett-Packard, DE, USA). Electrospray ionization (ESI) mode was selected as the ionization system. A Shodex RSpak NN-614 (Showa Denko, Tokyo, Japan) packed with a hydrophilic resin-based cation exchange resin (cation exchange capacity of 0.1 $\mathrm{meq} / \mathrm{g}$ ) was chosen as the separation column. The separation conditions were set by referring to those of the previous paper. ${ }^{7}$

Influence of postcolumn addition of methanol on sensitivity of arsenic compounds

Figure 1 shows the relationships between the flow rate of methanol added by postcolumn addition and the peak areas of arsenic compounds. The graph demonstrates that the addition of methanol to the mobile phase was effective for increasing the sensitivity, and that around $0.2 \mathrm{ml} / \mathrm{min}$ was a suitable rate for the high sensitive detection. The reason for increasing of sensitivity is that the methanol allows the surface tension of droplet from nebulizer. To decrease is consequently easier to make smaller droplets and to vaporize the liquid of droplet than without the addition of methanol. 

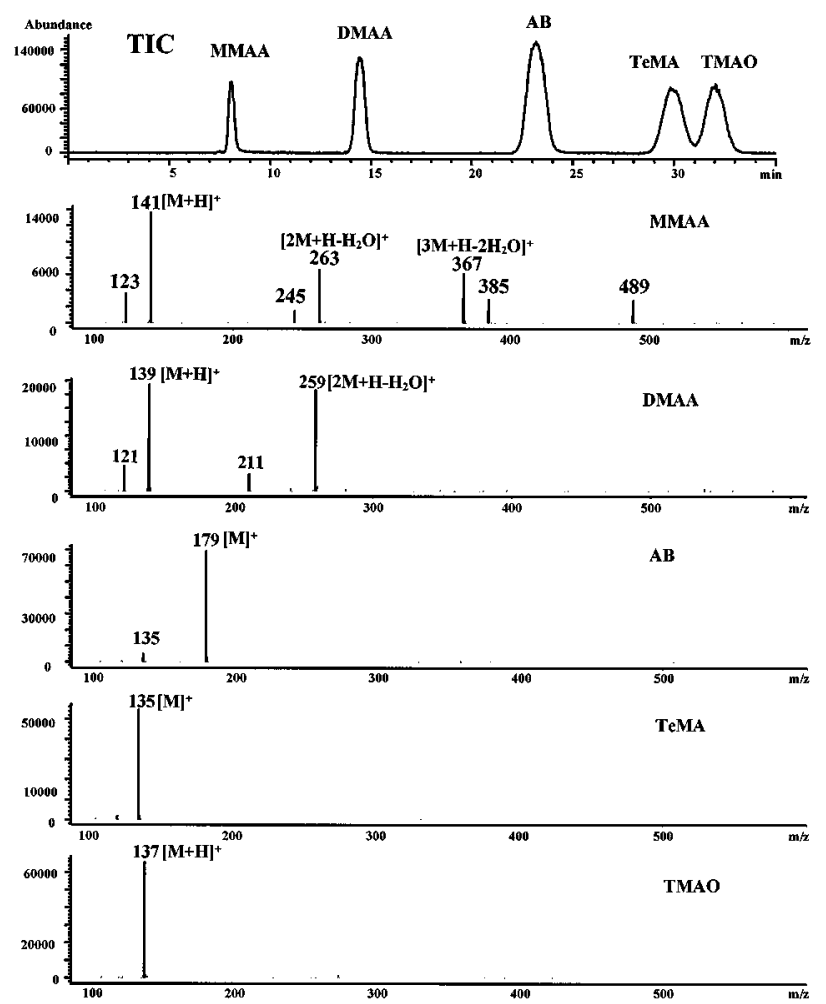

Fig. 2 TIC and mass spectra of arsenic compounds. Conditions: column, Shodex Rspak NN-614, mobile phase, 8 $\mathrm{mM} \mathrm{HNO}_{3} / 5 \mathrm{mM} \mathrm{NH} \mathrm{NO}_{3}, 0.4 \mathrm{ml} / \mathrm{min}$; temperature $40^{\circ} \mathrm{C}$; sample, $100 \mathrm{ng} / \mu \mathrm{l}$ each, $20 \mu \mathrm{l}$ inject. Postcolumn, methanol $0.2 \mathrm{ml} / \mathrm{min}$. Other conditions are those given in Fig. 1 .

On the other hand, the sensitivity was decreased over $0.2 \mathrm{ml} / \mathrm{min}$ flow rate. We think the reason for this decreasing of sensitivity is the dilution by methanol and the decreasing of vaporization rate of liquid droplet according to the increasing of the total flow rate. Furthermore, it was found that the addition of methanol could cause decreasing the formation of spike noise to decrease.

\section{Mass spectra of arsenic compounds}

Figure 2 shows the total ion chromatogram (TIC) and mass spectra of arsenic compounds. In MMAA and DMAA spectra, there were dimer $\left[2 \mathrm{M}+\mathrm{H}-\mathrm{H}_{2} \mathrm{O}\right]^{+}$or trimer $\left[3 \mathrm{M}+\mathrm{H}-2 \mathrm{H}_{2} \mathrm{O}\right]^{+}$ions and dehydrated ions $\left[\mathrm{M}+\mathrm{H}-\mathrm{H}_{2} \mathrm{O}\right]^{+}$with $[\mathrm{M}+\mathrm{H}]^{+}$. On the other hand, $[\mathrm{M}]^{+}$or $[\mathrm{M}+\mathrm{H}]^{+}$were obtained in $\mathrm{AB}, \mathrm{TeMA}$ and TMAO spectra. The fact that there were dimer ions in both compounds and a trimer ion in MMAA suggested that hydroxy group caused the dimer and trimer ions.

Detection limits, calibration curves of arsenic compounds

The calculated detection limit ( $\mathrm{pg} / \mu \mathrm{l}, S / N=3$ ) from the selected ion monitoring (SIM) chromatograms (10 $\mathrm{pg} / \mu \mathrm{l})$ were as follows: MMAA, 1.7; DMAA, 1.7 ; AB, 0.8 ; TeMA, 6.8; TMAO, 1.7. The linearity values were good from 10 to $500 \mathrm{pg} / \mu \mathrm{l}$ and the coefficients of correlation were over 0.998 on all arsenic compounds.

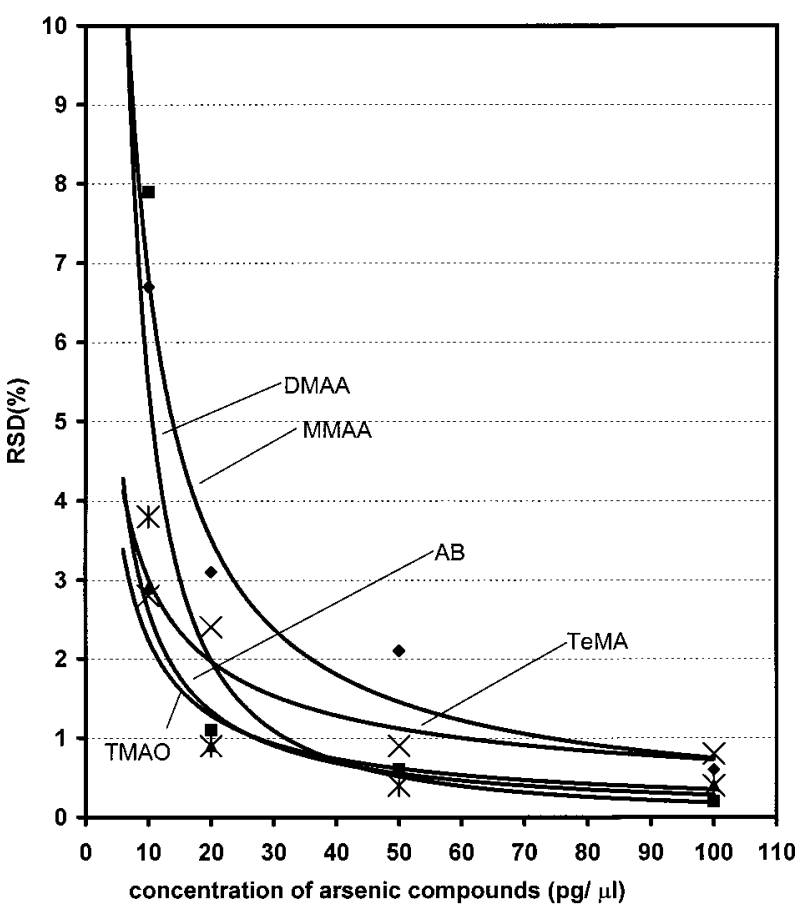

Fig. 3 The relationship between relative standard deviation (RSD) and the concentration of arsenic compounds. Positive SIM mode: sample, $10 \mathrm{pg} / \mu \mathrm{l}$ to $100 \mathrm{pg} / \mu \mathrm{l}$ each; postcolumn, methanol $0.2 \mathrm{ml} / \mathrm{min}$. Other conditions are those given in Fig. 2.

\section{Repeatability of peak area of arsenic compounds}

Figure 3 shows the relationship between relative standard deviations (RSD) and the concentration of arsenic compounds. Since the RSDs (\%) of peak area were under $10 \%$ from $10 \mathrm{pg} / \mu \mathrm{l}$ to $100 \mathrm{pg} / \mu \mathrm{l}$, it was found that the repeatability of this method was good. In our previous study the RSD (\%) of $50 \mathrm{pg} / \mu \mathrm{l}$ of arsenic compounds without postcolumn addition of methanol were $3-5(\%)$ against $0.5-2(\%)$ with postcolumn addition in Fig. 3. I think the reason of RSD (\%) drop without postcolumn addition is the formation of spike noise and the increasing of baseline noise.

\section{LC/MS of arsenic compounds spiked in urine}

Figure 4 shows the SIM chromatograms of arsenic compounds spiked in human urine. Table 1 shows the results of DMAA and AB spiked in urine. The concentrations of MMAA, TeMA and TMAO could not be determined because of the interference of background peaks from organic compounds in urine. The result of statistical analyses of peak areas and concentrations showed that the linearity of calculated values and observed ones was good. Although the LC/MS using the IC column could not determine spiked MMAA, TeMA and TMAO in urine, a pretreatment of sample, except for cation exchange mode column chromatography, will be effective to remove the interference of background peaks. The results of this research show that the combination of ESI with postcolumn addition of methanol and IC column in LC/MS for arsenic com- 

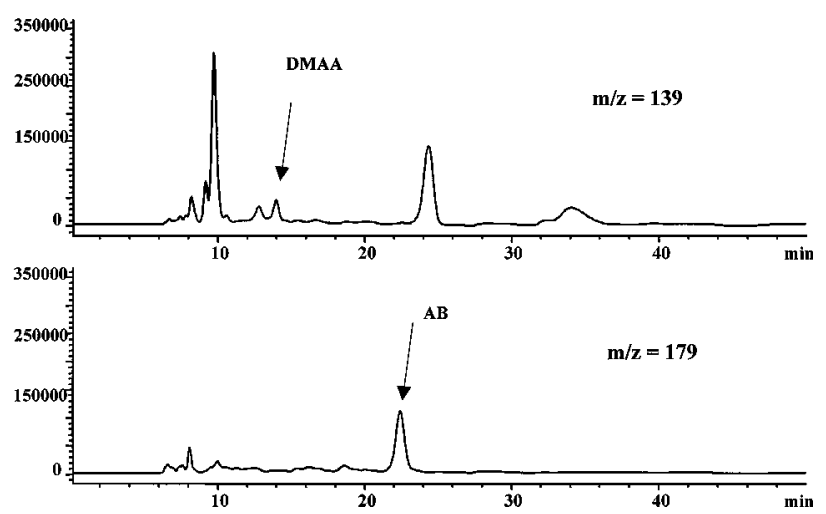

Fig. 4 SIM chromatograms of arsenic compounds spiked in urine. Positive SIM mode: sample, $100 \mathrm{pg} / \mu \mathrm{l}$ each spiked in urine; postcolumn, methanol $0.2 \mathrm{ml} / \mathrm{min}$. Other conditions are those given in Fig. 2.

pounds are effective for better quantitative and qualitative analysis.

\section{References}

1. IARC, "Monographs on the Evaluation of the Carcinogenic Risk of Chemicals to Man: Some Metals and Metallic Compounds," Vol. 23, p. 39, International Agency for Research on Cancer, Lyon, 1980.
Table 1 Concentration and recovery of spiked DMAA and $\mathrm{AB}$ in human urine

\begin{tabular}{ccccccc}
\hline \multirow{2}{*}{$\begin{array}{c}\text { Spiked } \\
\text { concentration }\end{array}$} & \multicolumn{2}{c}{ Concentration $^{\mathrm{a}} / \mathrm{pg} \mu \mathrm{l}^{-1}$} & & \multicolumn{2}{c}{ Recovery, \% } \\
\cline { 2 - 3 } \cline { 6 - 7 } & DMAA & $\mathrm{AB}$ & & DMAA & $\mathrm{AB}$ \\
\hline $100 \mathrm{pg} / \mu \mathrm{l}$ & 128 & 113 & & 128 & 113 \\
$200 \mathrm{pg} / \mu \mathrm{l}$ & 244 & 211 & & 122 & 106 \\
$400 \mathrm{pg} / \mu \mathrm{l}$ & 437 & 427 & & 109 & 107 \\
\hline
\end{tabular}

a. Average values $(n=3)$.

2. M. F. Hughes, M. M. Menache and D. J. Thompson, Fund. Appl. Toxicol., 22, 80 (1994).

3. E. Marafante, V. Vahter, H. Norin, J. Envall, M. Sandstom, A. Christakopoulos and R. Ryhage, J. Appl. Toxicol., 7, 111 (1987).

4. Y. Inoue, K. Kawabata, H. Takahashi and G. Endo, J. Chromatogr. A, 675, 149 (1994)

5. Y. Inoue, Y. Date, K. Yoshida, H. Chen and G. Endo, Appl. Organomet. Chem., 10, 707 (1996).

6. M. Careri, A. Mangia and M. Musci, J. Chromatogr. A, 727, 153 (1996)

7. Y. Inoue, Y. Date, T. Sakai, N. Shimizu, K. Yoshida, H. Chen, K. Kuroda and G. Endo, Appl. Organomet. Chem., 13, 81 (1999).

(Received December 22, 1998) (Accepted April 8, 1999) 